\title{
O AMÁLGAMA ATOR-PERSONAGEM: DA MÍMESIS TRANSPARENTE À ATUAÇÃO EXPERIMENTAL
}

\author{
THE ACTOR-CHARACTER AMALGAM: FROM TRANSPARENT MIMESIS TO \\ THE EXPERIMENTAL ACTING
}

\section{LA AMALGAMA ACTOR-PERSONAJE: DE LA MÍMESIS TRANSPARENTE A LA ACTUACIÓN EXPERIMENTAL}

Pedro Maciel Guimarães'

Sandro Oliveira ${ }^{2}$

Resumo: a relação ator-personagem é um dos pilares da prática atoral. Nosso objetivo é pensar relações entre essas instâncias enunciativas que extrapolem uma relação de simbiose, em que a primeira tenta se transformar na segunda, modelo clássico de atuação no teatro e no cinema. Propomos investigar estratégias de encenação onde ator e personagem são unidos pela ideia do amálgama total, por se unirem por uma condição física ou psicológica comum determinante. Para tal, utilizamos a metodologia dos estudos atorais, buscando desenvolver uma análise estética sobre processos e produtos de atuação (gestos, postura corporal) em filmes nos quais atores-personagens são acometidos por algum tipo de condição especial (nanismo, malformação congênita, síndrome de Down, surdez ou deficiência intelectual) o que faz com que haja interdependência essencial entre representação e referente. Tais procedimentos divergem da ideia tradicional de acoplamento ou de imitação, característica da mímesis transparente. A hipótese que se defende é que o amálgama total ator-personagem é um

Doutor em Cinema e Audiovisual pela Universidade Sorbonne Nouvelle (Paris III). Professor do Departamento de Cinema e do Programa de Pós-Graduação em Multimeios (Unicamp), Campinas, SP, Brasil https://orcid. org/o000-0002-5366-1481.E-mail: pedromacielguimaraes@gmail.com

2 Doutorando no Programa de Pós-Graduação em Multimeios (Unicamp). Professor do Departamento de Cinema e Audiovisual da Universidade Estadual de Goiás (UEG), GO, Brasil. https://orcid.org/oooo-0001-57178991 E-mail: nagysandro1@gmail.com 
procedimento, experimental, poucas vezes atingido no cinema de vertente comercial, como podem atestar os poucos exemplos de filmes aqui citados.

Palavras-chave: Estudos atorais. História e estética do cinema. Cinema experimental.

Abstract: the actor-character relationship is one of the pillars of the film acting. Our objective is to think of relations between these enunciative instances that extrapolate a symbiosis relation, in which the former tries to "transform" into the second, classic model of acting in the theater and in the cinema. We propose to investigate strategies of staging where actor and character are united by the idea of total amalgam, by being united by a determinant common physical or psychological condition. To that end, we used the methodology of the acting studies, seeking to develop an aesthetic analysis about processes and products of action (gestures, body posture) in films in which actor-characters are affected by some type of special condition (dwarfism, congenital malformation, Down syndrome, deafness or intellectual disability), which means that there is an essential interdependence between representation and referent. Such procedures diverge from the traditional idea of coupling or imitation, characteristic of transparent mimesis. The hypothesis is that the total amalgam actor-character is a procedure, experimental, rarely achieved in commercial cinema, as to the few examples of films cited here can attest.

Keywords: Acting studies. History and aesthetics of film. Experimental cinema.

Resumen: La relación actor-personaje es uno de los pilares de la práctica atoral. Nuestro objetivo es pensar relaciones entre esas instancias enunciativas que extrapolan una relación de simbiosis, en la que la primera intenta transformarse en la segunda, modelo clásico de actuación en el teatro y en el cine. Proponemos investigar estrategias de escenificación donde actor y personaje están unidos por la idea de la amalgama total, por unirse por una condición física o psicológica común determinante. Para ello, utilizamos la metodología de los estudios atorales, buscando desarrollar un análisis estético sobre procesos y productos de actuación (gestos, postura corporal) en películas en las cuales actores-personajes son acometidos por algún tipo de condición especial (enanismo, malformación congénita, Síndrome de malnutrición, Down, sordera o deficiencia intelectual) lo que hace que haya interdependencia esencial entre representación y referente. Estos procedimientos difieren de la idea tradicional de acoplamiento o de imitación, característica de la mímesis transparente. La hipótesis que se defiende es que la amalgama total actor-personaje es un procedimiento, experimental, pocas veces alcanzado en el cine de vertiente comercial, como pueden atestiguar los pocos ejemplos de películas aquí citadas.

Palabras clave: Estudios actorales. Historia y estética del cine. Cine experimental. 


\section{Introdução}

Na história do cinema mainstream, ou o que muitos teóricos chamam de cinema comercial ou clássico, personagens são criados para se conformarem a padrões de aceitabilidade que se transformam muito lentamente através do tempo. Na época considerada clássica pela historiografia dominante, que vai basicamente do final dos anos 1920 até final dos anos 1950, as tramas se apresentavam, majoritariamente, em torno de um casal heterossexual branco, de classe média, os WASP (White, Angle-Saxon Protestant) ${ }^{3}$, com seus problemas afetivos e profissionais - salvo, é claro, algumas exceções ${ }^{4}$. Do ponto de vista psicológico e físico, esses personagens gozavam de perfeita saúde, tinham um physique apropriado ao gosto do público e, com marcadas exceções, doenças, deformidades ou qualquer tipo de afecção ou déficit intelectual tinham vez nas narrativas. No rol das exceções, alguns gêneros como os melodramas, dramas românticos ou biopics abriam espaço para personagens com enfermidades ou debilidades físicas e mentais: a cegueira, a surdo-mudez, as debilidades locomotivas, paralisias parciais, etc.

A mímesis transparente a que se refere esse artigo, elemento a partir do qual queremos propor uma antítese discursiva que chamamos atuação experimental, é o processo de imitação corporal de personagens com qualquer tipo de deficiência ou restrição física ou mental que fosse mediada por atuações baseadas na autoridade e competências do ator profissional, capaz de figurar tais condições restritivas de maneira convincente e psicologicamente embasada. Valorizar-se-ia, assim, o trabalho do ator profissional como uma construção comunicacional e gestual baseada na capacidade da imitação em criar analogia credível entre a representação (o personagem) e o referente (pessoa real acometida de alguma enfermidade). Tal estratégia propiciaria um verniz de aceitabilidade imagética a esses seres fadados à invisibilidade. A mímesis transparente é, portanto, o equivalente do processo clássico da imitação atoral baseado na comparação verossímil com alguma realidade corporal existente no mundo concreto. $\mathrm{O}$ resultado desse processo, a forma visual apreendida na tela, responde então ao percurso desse processo de construção de uma comunicação gestual coerente e equilibrada, atendendo aos princípios de

\footnotetext{
3 Protestante branco e anglo-saxão.

4 Para James Naremore (1988, p. 23), a Lilian Gish dos anos 1920 encarna o ideal do WASP, com seu "rosto de porcelana e traços regulares e delicados", rosto esse que pode ser encontrado à profusão, no período que vai até o final dos anos 1950, quando outro rosto de porcelana, o de Lana Turner em Imitação da vida (Imitation of life, Douglas Sirk, 1959) pode representar o ocaso dessa estética.
} 
aceitabilidade, progressão psicológica e compreensão imediata dos signos visuais, colaborando na tão buscada impressão de realidade da imagem fílmica.

$\mathrm{Na}$ história do cinema, a malformação física ou as deficiências intelectuais têm sido, com raras exceções, um tabu de ordem ética e estética: ou se trata do tema com um simulacro palatável para o grande público, usando-se atores profissionais e formas comedidas, ou se relega essas deficiências ao silêncio do esquecimento e dos arcabouços dos temas intratáveis. Há, nesses cinemas, um claro favorecimento da performance atoral, um produto visual que é o estágio final de um processo cujo suporte é o corpo e a persona do ator. Paralelamente a isso, preza-se pela sobrevalorização do (a) ator/atriz que se traveste, na maioria dos casos atores-estrelas, que se muta, que se torna (quase) fisicamente irreconhecível. Almeja-se assim o acoplamento do ator ao personagem, uma interdependência estruturante entre ambos. O que mais se nota no julgamento de sua capacidade profissional é a autoridade da transformação e, por conseguinte, a eficiência na recriação de um mundo e de seres tais quais se apresentam aos olhos do público: mundo e seres impregnados pela impressão de realidade, o suporte da mímesis transparente. Forja-se então, na história desses cinemas, a autoridade da imitação como fator de mérito da atuação.

Para consubstanciar esta autoridade da imitação, existem filmes em que atores/ atrizes profissionais encenam condições especiais, explicitando a tentativa de acoplamento e intimidade fictícia entre essas duas instâncias: corpo e subjetividade do ator/corpo e subjetividade do personagem. Os exemplos abundam: a surdo-mudez de Belinda MacDonald (Jane Wyman) em Johnny Belinda (Belinda, John Negulesco, 1948), a cegueira e surdez de Patty Duke (Hellen Keller) em O milagre de Anne Sullivan (The miracle worker, Arthur Penn, 1962), a paraplegia de Luke Martin (Jon Voigt) em Amargo Regresso (Coming home, Hal Ashby, 1978), a síndrome de Proteus de John Merrick (John Hurt) em O homem elefante (The elephant man, David Lynch, 1980), o autismo de Raymond Babbit (Dustin Hoffman) em Rain man (Barry Levinson, 1988), a paralisia mental de Christy Brown (Daniel Day Lewis) em O meu pé esquerdo (My left foot, Jim Sheridan, 1989) e os diversos casos de cegueira, talvez a deformidade física mais mimetizada por atores na história do cinema como Virginia Cherrill em Luzes da Cidade (City lights, Charles Chaplin, 1931), Jane Wyman em Sublime Obsessão (Magnificent obsession, Douglas Sirk, 1954), Ida Lupino em Cinzas que queimam (On dangerous ground, Nicholas Ray, 1951) e Al Pacino em Perfume de mulher (Scent of a woman, Martin Brest, 1992). Os paratextos desses filmes apostam justamente em uma certa capacidade de convivência entre ator e personagem 
e, mais especificamente, nas habilidades do ator-estrela de se transformar em determinado personagem acometido por debilidade física ou mental ${ }^{5}$.

Essas atuações adequam-se ao cinema como processo artístico representativo onde atores encenam personagens nos quais eles devem se transformar através de pesquisa, do estudo psicológico e gestual das ações físicas, onde o ator deveria '[...] 'viver' o personagem que ele/ela interpreta, tão completamente quanto possível, e deveria basear sua performance no que este personagem sente por dentro" [grifo nosso] (DYER, 1998, p. 132, tradução nossa) ${ }^{6}$. Esse modelo, dominante e segregador, recorreu com frequência a personagens reais e serviu como garantia de mérito do jogo atoral, visto a enxurrada de prêmios que receberam a maioria das performances citadas.

Na contramão de tal modelo de atuação, estrutura-se outro procedimento no qual o resultado do processo de fusão física entre ator e personagem se dá não somente através de procedimentos de jogo tradicionais (laboratório, imitação detalhada, recursos a efeitos de visagismo e figurino) e que pretendem apagar o ator em detrimento do personagem. Nosso objetivo neste artigo é analisar esse modelo de atuação e de comunicação gestual, uma representação analógica, segundo Barthes (1964, p. 40), que consolida a ideia do amálgama físico total pelo fato de que o elemento humano (ator profissional ou não) se torna indissociável do personagem por possuir determinada condição física ou mental - condição essa que se torna, na quase maioria dos casos, o fato que promove, através da superação e aceitação, a trama dos mesmos. Personagem e ator acometidos pela mesma deficiência onde a de um se torna condição sine qua non para a do outro. Alguns filmes espraiados pela história e pela geografia do cinema trabalharam nessa estética: deformidades de distintas ordens em Monstros (Freaks, Tod Browning, 1932, EUA); a surdo-mudez de Marlee Matlin em Filhos do Silêncio (Children of a lesser God, Randa Raines, 1986, EUA); o nanismo de Alejandra Podestá De eso no se habla (Maria Luisa Bemberg, 1993, Argentina); a síndrome de Down de Pascal Duquenne em O Oitavo Dia (Le huitième jour, Jacob Van Dormael, 1996, França); e deformidade e insuficiência intelelectual de Madi Ekhtiar-Dini em Tempo de embebedar cavalos (Zamani barayé masti asbha, Bahman Ghobadi, 2000, Irã)ํ. Nesses

\footnotetext{
5 Aqui, citamos filmes que extrapolam os limites do cinema clássico descritos pela historiografia dominante, prova de que essa marca histórico-estética usada pelos manuais de cinema não se restringe ao período que vai dos anos 1920 aos 1950.

6 Do original: [...] 'live' the character s/he plays as fully as possible and should base the performance on how s/ he feels inside.

7 Existem outros filmes que poderiam estar nessa lista, como Os melhores anos de nossas vidas (The best years o four lives, William Wyler, 1946), cujo personagem Homer Parrish, sobrevivente de guerra, é vivido por um
} 
filmes, todos com personagem com algum tipo de condição especial (nanismo, malformação congênita, amputação, síndrome de Down, surdez ou deficiência intelectual) em que os atores ou atrizes, profissionais ou não, em vez de serem contratados para mimetizaram tais deficiências, efetivamente possuem aqueles tipos de condição especial, promovendo um amálgama total entre ator e personagem, resquício ou marca indelével de uma experimentalidade no casting desses filmes. Se, no primeiro caso, falamos de transformação (acoplamento, simbiose, convivência), aqui o amálgama prevê, como descreve esse termo de origem cientifica, a junção total entre partes ou elementos distintos.

Nosso artigo inscreve-se na metodologia de estudos da atuação no cinema, os acting studies (estudos atorais), que buscam desenvolver um ângulo de análise estética sobre processos e produtos de atuação feito por atores profissionais ou não profissionais, em confluência com outras dimensões de criação de significado dentro do filme (relação ator/mise-en-scène, ator/realizador, ator/textos parafílmicos). Segundo Damour (2016, p. 10), os estudos atorais propõem tecer considerações estética sobre todos os tipos de atores, e não apenas os atores-estrelas, e entender a performance atoral como resultado da utilização dos signos visuais do seu corpo (gestos, postura corporal, uso da voz, tipologias de personagens) empregado num processo comunicacional.

Defendemos que os procedimentos de atuação definem os rumos estéticos do filme, desde seus processos de criação até os de recepção. No caso do amálgama ator-personagem, abordaremos um tipo de escolha de atores baseados na experimentalidade, visto que se trata de um regime de exceção, em que as condições especiais desses personagens acabam sendo a condição principal de escolha do ator, superando alguns ditames principais do casting de filmes comerciais : apelo do ator junto ao público, qualidade de estrela, possibilidade de financiamentos mais vultosos, garantia de uma formação profissional capaz de transpor para a tela as nuances e versatilidades da atuação teatral, etc. Algo similar ocorre na representação étnica, em que grupos sociais são representados através do recurso a efeitos de maquiagem para que o ator se pareça com o tipo físico retratado, exemplo dos diversos atores caucausianos que viveram indígenas ou latino-americanos no cinema americano clássico: Rock Hudson, Jack Palance, Jennifer Jones e outros.

verdadeiro veterano, Harold Russel, que teve as mãos amputadas na II Guerra Mundial. Citamos esses pelo fato de configurarem nosso corpus de análise. 
Existe, apesar de toda diferença estética, visual e conceitual entre filmes considerados experimentais, independentes e modernos pela historiografia do cinema, todos opostos ao classicismo do discurso do cinema comercial, uma questão ética no campo do casting que os une e que merece ser analisada. Que tipo de ator/modelo/ tipo busca-se para um filme? Isso acarreta uma série de assunções que o público fará sobre que tipo de filme está vendo e que tipo de relação irá empreender com os atores/ atrizes e, por conseguinte, com a obra. A ética da qual se comenta aqui é a da escolha dos instrumentos que o ator se utilizará para atingir o sublime da arte, ou seja, o canal ideal de comunicação com o público, a verdade da imitação.

\section{Da possibilidade de transformação do ator ao amálgama}

Apesar do cinema clássico de Hollywood ter levado o primado da semelhança morfológica entre ator e personagem para dentro dos princípios básicos de casting e atuação, a questão do encaixe perfeito entre essas duas instâncias significantes nunca possui uma ilusão completa, pois sempre sabemos que se trata de um ator representando um personagem: "a personificação no filme de ficção, especialmente quando executada por um astro, tem um efeito paradoxal; quanto mais perfeito ela é, mais consciente nós estamos do ator que a efetua" (NAREMORE, 2012, p. 38, tradução nossa) ${ }^{8}$. Esse paradoxo recobre outro ainda maior, o que envolve o ator em uma rede de produção de sentido visando o retorno financeiro dos filmes. O star system baseia-se, de fato, no paradoxo entre a capacidade da prática atoral de se camuflar por detrás do personagem e a possibilidade de uma obra ser mais rentável justamente em cima das capacidades de atração dessa estrela de cinema que se transforma em um personagem. Com raras exceções, como no caso de personagens de heróis de histórias em quadrinhos ou franquias de personagens literários (Harry Potter, James Bond, Hannibal, o canibal), quem se incumbe de atrair o público para o cinema é o ator e, em muitos casos, a capacidade física do ator de se transmutar num personagem : vide o estardalhaço midiático feito a cada nova aparição de Meryl Streep ou Daniel Day Lewis na pele de personagens distintos entre si. Este hiato entre o corpo do ator e o personagem já estava também presente na reflexão de Diderot para quem o paradoxo do comediante está justamente no fato de que

\footnotetext{
8 Do original: [...] impersonation in fiction film, especially when performed by a star, has a paradoxical effect;
} the more perfect it is, the more conscious we are of the performer who accomplishes it. 
o ator "[...] não adere à personagem que faz viver. Ele lhe empresta seu corpo ..." (1979, citado por GALARD, 2008, p. 112). A Hollywood clássica apenas atualiza o princípio secular do pensador francês, retrabalhado para o caráter de consumo em massa próprio ao cinema.

Roubine (2002, p. 49) enxerga nessa relação ator-personagem uma questão ideológica mais aguda, "um problema mal colocado pela ideologia dominante do 'natural'”, pois afirma que o cinema nos acostumou a não aceitar atores que não tivessem suficientes características físicas do personagem. Há aqui uma dupla via de análise do corpo do ator naturalista clássico, pois ao mesmo tempo que é maleável, feito para não ser percebido, para habilmente não chamar a atenção para a sua autoridade da imitação, esse corpo ascende ao universal, nas palavras de Nicole Brenez, pois o ator clássico está em cena por todo outro corpo que o espectador gostaria de lhe sobrepor ou de lhe substituir, "corpo, como todo corpo, atravessado pelo coletivo e assim, excedendo a obra na qual ele pertence, o ator [...] a conclama ao universal" (BRENEZ, 1991 citado por AUMONT, 1992, p. 50, tradução nossa) ${ }^{9}$. Contudo, se esse corpo ascende a um patamar de aceitabilidade para públicos tão vastos, era em razão de algo que o capacitava para tal: um padrão de homogeneidade, equilíbrio e desejo que tem sido incansável objeto estético do mundo da moda, da publicidade, da saúde pública, de um certo ideal coletivo de saúde corporal ligado tanto a um modelo orgânico (norma) quanto a uma questão mais abrangente e maleável, o ideal da beleza (forma) ${ }^{10}$.

E nesse ideal de beleza, marcado por corpos masculinos viris, mas que poderiam ser caracterizados como os do homem comum e corpos femininos longilíneos, ágeis, "hieráticos e de aura romântica" (BOURGET, 2005, p. 145) e ferozmente produzidos por uma ideia eugênica de perfeição, o corpo deformado, ou o ser humano que não se conforma com os padrões de aceitabilidade da indústria de massa, são relegados a segundo plano ou retirados totalmente de cena. 0 restrito número de filmes citados na introdução com atores verdadeiramente portadores de disfunções físicas ou mentais prova esta hipótese: não há espaço para uma desorganização dos primados de aparências já tão solidamente fincados no mundo do cinema industrial. Pulverizar e demolir aparências, derrubando

\footnotetext{
9 Do original: (...) corps comme tout corps traversé par le collectif et en cela, excédant l'oeuvre à laquele il participe; l'acteur [...] en appele à l'universel".

10 AUMONT, Jacques. O olho interminável [Cinema e pintura], p. 213. Aumont afirma que a distorção de um modelo, sua deformação, toma uma distância em relação à norma e à forma na relação da pintura com o cinema, da tela do pintor com a tela do cinema. Os conceitos aqui de norma e forma são propostos na relação de base com os termos usados por Aumont, mas deslocados para o âmbito do corpo, sua relação com modelo e beleza e, como no caso deste trabalho, ligados ou não a uma deformação ou distorção.
} 
preconceitos e fazendo aflorar a materialidade do corpo do ator portador de alguma deformação, pode ser altamente subversivo no cinema de veiculação a grandes públicos transnacionais, só possível para um teórico como Antonin Artaud, criador do rigor cego a um ator que choca pela sua crueldade, destruindo, na opinião de Brenez, a própria circulação simbólica desses corpos (BRENEZ, 1998).

É sintomático então, no percurso amplo do cinema clássico, que sejam atores profissionais que interpretem papéis de personagens com deformações reais, pois o uso de atores com reais deformações desestabilizaria, na ordem do figurativo, a regularidade já posta, verdadeiramente instituída, de uma aceitabilidade corporal que rejeita essas pesquisas experimentais de aspecto teratológico presentes nos poucos filmes com atores deformados ou acometidos por afecções mentais. A busca pela verdade da atuação deixou de se apoiar nas possibilidades naturais que os corpos dos atores trariam e passou a contar com aspectos culturais como a sistemática do gestual e o uso do signo corporal retrabalhado por técnicas teatrais para se transformarem em elementos de criação de sentido e portadores de afeto dentro das tramas. Foi preciso contar com o cinema moderno a partir dos anos $1950^{11}$ para que tal lógica fosse minimamente abalada de maneira mais consistente - ambiente no qual incluímos também os cinemas experimentais de diversos países.

\section{Ética e mérito nas atuações amalgamadas}

Dois dos filmes citados na introdução lidam com o nanismo como tema, a sempre delicada questão da aceitação social, modelos de adaptabilidade e a proposta política da inclusão social: Monstros e De eso no se habla. É incrível a coincidência de destinos que esperam os protagonistas desses filmes, Hans (Harry Earles) e Charlotte (Alejandra Podestá), tão distantes no espaço (EUA e Argentina), personagens presentes em produções cinematográficas pertencentes a realidades temporais radicalmente diferentes: o filme americano é de 1932 e pertence à enorme leva da produção dos estúdios da MGM logo após a depressão, já o argentino é uma coprodução independente de 1993.

\footnotetext{
"Para Alain Bergala ([2005]), em L'Invention de l'acteur moderne, o ator portador de alguma deformação física ou incapacidade mental tem uma origem ético-artístico: as imagens dos campos de concentração após a $2^{\text {a }}$ Guerra Mundial e a fobia do corpo glorioso, da estrela (star) com o seu corpo de perfeita e pura luz. Assim, faz-se retornar à voga o corpo real, comum e orgânico - questionando o ator protegido do cinema clássico -, para o ator carnal e exposto dos cinemas modernos: o ator atua o que ele é.
} 
Esses filmes tratam da deformidade como "um constructo social formado por percepções, palavras e imagens, e não [como] um fenômeno natural" (WILLIAMS, 1999, p. 47). Isso acarreta uma visão de seus protagonistas, que é um tratado sobre questões de autoidentidade e de um ideal essencializado: uma metáfora para qualquer tipo de diferença. Hans e Charlotte enxergam na diferença de seus corpos algo desprezível e insignificante - o mesmo caso do anão do espetáculo circense em Monstros, com seus modos cavalheirescos e aristocratas - ou a ignoram peremptoriamente, no caso de Charlotte, no seu mundo profundamente restrito e protegido pela sua mãe dominadora. Hans enxerga no mundo a delicadeza de gestos e o desprezo pelas diferenças como questões culturais que possam separar as pessoas, fazendo com que ele caia numa malha de tramas ao se envolver com a trapezista não anã, Cleópatra, interessada na herança que ele receberá. Charlotte simplesmente ignora qualquer diferença, vivendo numa espécie de contos de fadas de família de classe média, uma bolha forçada de tolerância forjada pela mãe, com suas aulas de piano e recitais.

Os atores Harry Earles e Alejandra Podestá e os personagens que encarnam possuem uma inquestionável dependência da relação entre os traços físicos, dependência essa que, de tão inalcançável por um ator não anão, se torna mais intensa, até arrebatadora. Difícil pensar em outro tipo de personagem que não demande o amálgama com seu ator como o daqueles atingidos por nanismo talvez apenas os com síndrome de Down -, justamente por não se tratar apenas da baixa estatura, mas de uma série de signos visuais no rosto e corpo impossíveis de serem mimetizados a contento. $\mathrm{O}$ ator com nanismo e os personagens que ele ou ela, por ventura, interpretarem, prolongar-se-ão ad infinitum, numa ligação que será de tão inquebrantável, extremamente fundida: a intensidade do ator sob o personagem será tão intensa quanto a do ator sobre a personagem. Há aqui algo que limitaria sobremaneira o trabalho do ator com nanismo, pois ele frequentemente irá trazer nas marcas do seu corpo gestos, posturas ou índices variados de sua vida fora da tela, sendo incapaz de se desvencilhar deles, para o bem e para o mal, no ato da interpretação: a maleabilidade física, tão valorizada no ator clássico, lhe é uma deficiência marcante. Ao contrário do que prega, então, Denise Schröpfer (2001, p. 63, tradução nossa), para quem o corpo do ator "é maior e mais expansivo que o corpo cotidiano"12, no caso do ator com

12 Do original: (...) est plus grand et plus porteur que le corps quotidien. 
nanismo, as características físicas do corpo cotidiano do ator também seriam levadas à tela, limitando (ou quase igualando) sobremaneira suas significações ${ }^{13}$.

O tipo de polêmica que se instala no cinema por conta de atores fora do métier artístico profissional ou não vedetes atuando nesses papeis limítrofes se aloja no fato de tal galardão poder ser entendido como uma limitação do trabalho do ator profissional, justamente em suas prerrogativas de se transformarem nos mais diferentes tipos. O discurso parafílmico de premiações da indústria premia também os atores amalgamados (Marlee Matlin ganhou o Oscar de Melhor atriz e Pascal Duquenne o prêmio de melhor atuação masculina por O oitavo dia, ao lado de um ator profissional, Daniel Auteuil) ressaltando que o mérito da atuação não está apenas em criar uma nova forma visual no espaço, mas que se leva em consideração também as particularidades do emissor dessa forma.

A presença de Duquenne nesse filme abre espaço para uma questão que parece estar soterrada por uma série de premissas intocadas no cinema mais marcadamente comercial: o fato de que existe um limite invisível, não demarcado, entre ator e personagem, o hiato que deve existir entre profissional contratado para atuar numa produção cinematográfica e o personagem que ele interpreta. Esse hiato é tão perceptível que Richard Dyer, fazendo uma análise ampla da sociologia e da semiótica do ator hollywoodiano, afirma que ocorre o que ele chama de perfect fit (encaixe perfeito), entre ator e personagem, somente quando:

[...] todos os aspectos da imagem de uma star se encaixam com os traços de um personagem. Ou seja, todos os vários signos do personagem, incluindo aqueles adquiridos através do uso de astros (stars), estão de acordo ${ }^{14}$ (DYER, 1998, p. 129, tradução nossa).

Essa polissemia do uso de atores do star system teria então, de acordo com Dyer (1998), de estar numa sintonia fina com aspectos físicos e psicológicos do personagem. No entanto, sintonia essa muito longe ainda do amálgama total que se propõe aqui entre ator e personagem, presente na escolha de Duquenne para o papel de Georges.

\footnotetext{
13 Dá para antever alguns sinais contemporâneos de disjunção entre a condição do nanismo e as características psicológicas do personagem baseadas na fragilidade ou incompreensão como demonstra a carreira de Peter Dinklage, em séries como Game of Thrones (produzida pela HBO) ou filmes como Três anúncios para um crime (Three Billboards Outside Ebbing, Missouri, Martin McDonagh, 2017), em que seus personagens são apenas secundariamente determinados pela condição do nanismo.

14 Do original: [...] all the aspects of a star's image fit with all the traits of a character. That is, all the various signs of character, including those achieved through the use of stars, accord.
} 
Sendo portador da síndrome de Down, Duquenne leva a um patamar poucas vezes atingido o armoured body de Wilhelm Reich (1949 citado por MIXON, 1983), um corpo blindado que expõe suas marcas imutáveis. Estes atores portadores de uma condição congênita, nitidamente notável na tela, trazem nos seus corpos as marcas do seu passado, das suas dores e feridas de uma maneira muito mais pungente do que atores profissionais comuns, ocasionando o que já foi explicitado acima sobre Earles e Podestá: eternamente fadados a exporem um corpo-signo único ou se não tanto, determinados na sua significação fílmica ao longo de todos os filmes em que atuarem.

Sobre a questão da inserção social e a aceitabilidade do personagem Georges (Duquenne), o filme mostrará caminhos para sua permanência fora dos meandros do orfanato para pessoas especiais: ser adotado pela irmã ou pelo amigo que ele encontra, Harry (Auteuil), nas suas andanças em busca por um lar que o acolha. Tendo as duas portas fechadas, o destino trágico de Georges pode ser lido como uma espécie de lição-sinédoque dos portadores da síndrome de Down e a sua conformação à sociedade dos "outros": ou a sociedade aprende a se adaptar às diferenças, ou elas irão se impor com a força de uma tragédia igual a de Georges.

O que nos é mostrado violentamente através da performance do ator com síndrome de Down é o seu caráter orgânico, a natural e desconcertante expressão de uma biologia exposta: a expressão plástica de seu corpo inteiro nos faz experimentar estados emocionais intensos, de uma confusão espectatorial causada pelo desconforto da exposição e observação continuada e emotiva de tão delicado amálgama. Algo semelhante ocorreu no cinema brasileiro recente em A pessoa é para o que nasce (Roberto Berliner, 2003), onde testemunhamos uma constrangedora confissão de amor de uma das personagens cegas acompanhadas pelo diretor, fazendo-nos questionar os princípios éticos do realizador em ter estabelecido tanta proximidade com suas "atrizes", débeis elos nessa maquinaria de manipulação da imagem e do desejo.

O prêmio de Duquenne recebido em Cannes não ficou imune às críticas. Talvez a mais incisiva, não somente à presença de um não profissional, mas também ao fato deste "ator"15 ser portador da síndrome de Down foi a de Jacqueline Nacache que afirmou que a presença de Duquenne é tão enganadora e tão destituída da solução ideal para o cinema que o filme tenta a todo tempo "esbater ${ }^{16}$ a diferença entre o verdadeiro e o falso" assim, o que "inquieta e constrange é essa repre-

\footnotetext{
15 Grifo da autora.

16 Esbater significa matizar, graduar, suavizar, atenuar.
} 
sentação ser obtida a partir da própria natureza do indivíduo, a partir daquilo que nele provém de algo que não seja uma simulação consciente". E continua:

Os corpos verdadeiros também são enganadores, e não constituem a solução derradeira para a mentira da representação. A ideia de um ator não-profissional, por isso não corrompido pela prática intensiva da simulação, parece estranha ao cinema, na medida em que a distância entre profissional e não-profissional é exatamente o que lhe tenta reduzir a representação (NACACHE, 2012, p. 126).

Há um problema de ordem ética em O oitavo dia ao propor, na opinião de Nacache (2012, p. 125), uma "irrupção de um corpo 'verdadeiro' num filme de ficção [que] não pode [nos] causar indiferença”, pois o trabalho de crianças-atores ou de pessoas com qualquer grau de deficiência apresenta uma manipulação inequivocamente clara - vide o caso da cena do ator-mirim chorando compulsivamente ao se ver ameaçado por uma arma de fogo em Cidade de Deus (Fernando Meirelles, Katia Lund, 2002). Métodos de direção à parte, o que não fica claro aqui é se Nacache está afirmando que esse grau de manipulação está somente no âmbito das escolhas artísticas eticamente equivocadas ou se ela aborda o alto grau de suscetibilidade emocional e uma óbvia incapacidade (ou capacidade reduzida) de atores não profissionais, com ou sem deficiência, em rebater a abusos que pudessem acontecer no set de filmagens, local histórico de fatos escabrosos envolvendo realizadores exigentes e atores/ atrizes emocionalmente frágeis.

Se Nacache critica a presença de crianças-atores ou não profissionais no elenco de filmes ficcionais em razão da fragilização do poder de simulação que o cinema nunca deve perder, os atores-crianças de Tempo de embebedar cavalos levam o esfumaçamento entre ficção e documentário a um patamar ainda mais desconcertante, propondo uma solução ainda mais distante à proposta pela teórica. Este filme carrega os primados do realismo à sua origem mais recôndita, no realismo-naturalista do século XIX, presente na literatura de Émile Zola (THOMPSON, 1988, p. 205 - 207). Primeiramente, uma noção ideológica dos trabalhadores sem qualificação profissional de áreas isoladas e carentes, no caso do filme de Bahman Ghobadi, o território do Curdistão ocupado pelo Irã, com sua enorme população apátrida e esquecida. Em seguida, uma objetividade geográfico-histórica com a construção de um universo diegético pleno e o uso de pessoas do lugar, dando um verniz de autenticidade aos gestos, à língua falada, aos costumes retratados próprios do neorrealismo italiano. Finalmente, um certo apego a uma temática do cotidiano de uma família de trabalhadores, com suas 
tarefas diárias, seus prazos, ocorrências fortuitas e o trabalho dos irmãos mais velhos no contrabando de produtos entre as fronteiras do Irã e Iraque.

Tempo de embebedar cavalos é a história de Ayoub (Ayoub Ahmadi), um menino de 12 anos que sustenta sua família de três irmãs e um irmão portador de malformação congênita que aparentemente possui também algum tipo de déficit intelectual: Madi (vivido pelo ator Madi Ekhtiar-dini). Ayoub trabalha carregando produtos que serão contrabandeados através da fronteira em guerra, até que recebem um ultimato do médico visitante que esporadicamente atende aos moradores da vila onde moram: se Madi não sofrer uma intervenção cirúrgica emergencial, ele não sobreviverá. É sobre o périplo que essa família de órfãos empreenderá que revolve o filme de Ghobadi.

$O$ ator com má formação congênita como no caso de Madi, se torna aqui, um performer, segundo argumenta Pavis (2011, p. 55), que "não representa um papel, [mas] age em seu próprio nome", pois o personagem carrega na sua própria carne algo tão intimamente ligado à identidade do ator, que fica próximo do impossível destacar um do outro ${ }^{17}$. Assim, este amálgama desconcertante entre ator-personagem ilumina a discussão instalada por Nacache, visto que o cinema documenta, em um filme de fundo ficcional, a possibilidade desse ator-personagem ruir ou desaparecer diante das câmeras. A ameaça que pesa sobre o personagem, física e hipotética, determina nossa percepção do ator, tornando-se, quem sabe, concreta e iminente.

A hipótese que este trabalho aventa é que há perdas e ganhos, pois exatamente a potência de impressão do "real" que o filme de Ghobadi nos lança talvez tenha, também, evidentes fragilidades. Como na cena em que Ayoub (Ayoub Ahmadi), o irmão mais velho de Madi, está numa espécie de pequena venda de bebidas e conversa com o menino garçom para combinarem a venda de algumas fotos que estão na parede. A impressão que se tem da conversa entre os dois, registrada num campo-contracampo tradicional, é de um total desconforto para os atores, não acostumados a terem "falas" tão longas e nem a encená-las para a câmera. $O$ ritmo e a dicção das palavras revelam um óbvio tom jogralesco juvenil, quando se tem a impressão de frases declamadas, num tom identificado nos padrões da teoria como "bressoniano", mas que são, no fundo, apenas ditas com pouca naturalidade.

17 O amálgama aqui é construído nesse filme também com um artifício já desgastado: o uso dos nomes reais dos atores nos personagens, artifício que já era utilizado no neorrealismo italiano e recorrente no cinema brasileiro contemporâneo. 
O que Tempo de embebedar cavalos tem de mais potente, mais assombroso na sua fatura é, indubitavelmente, a própria imagem gráfica do corpo de Madi, com suas pernas pequenas arqueadas, corpo minúsculo que se desloca com extrema dificuldade, num mundo hostil para alguém tão frágil e doente. Em alguns planos do filme, seu corpo é exposto a seco, em plano planimétrico, achatado, tendo em background pedras de um rochedo (Figura 1).

Figura 1 - Madi Ekhtiar-dini e seu corpo-silhueta

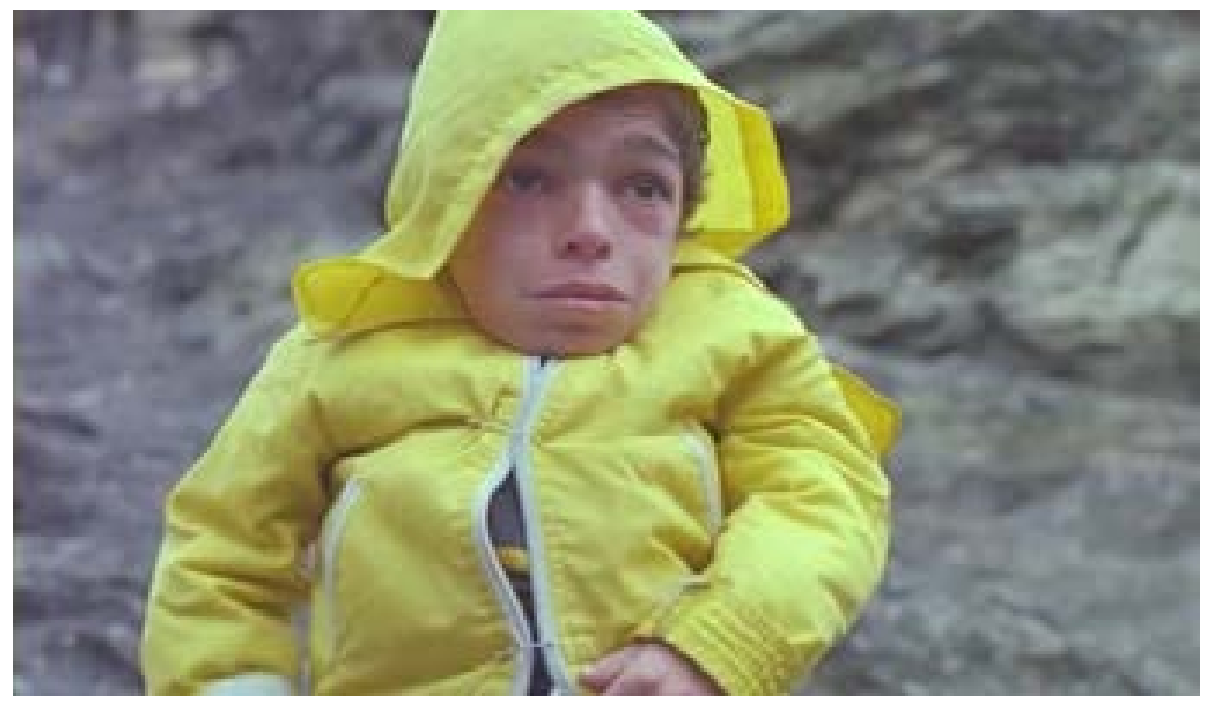

Fonte: Tempo de embebedar cavalos (Bahman Ghobadi, 2000).

Ghobadi implementa no campo do casting cinematográfico este corpo-silhueta da deformação de Madi; um personagem físico, estritamente definido por sua aparição corporal, um corpo que permanece por detrás da efígie na tela, já que, "porque há uma analogia, porque a imagem guarda o traço do indivíduo que é o ator ou o figurante, que o corpo subsiste" (BRENEZ, 1998, p. 31). Um corpo que permanece na nossa memória pelo seu estilo da exposição que é de tal grau de assombramento, que enfatiza não somente o tom "documental" do filme de Ghobadi, mas também reforça a hipótese deste trabalho sobre a experimentalidade na escolha de Madi Ekhtiar-dini no papel de Madi. Pode-se afirmar que é proveniente da observação concreta do seu corpo, do seu exterior, e não dos psicologismos que nos acostumou o cinema clássico, as emoções que sentimos, sejam elas tão contraditórias como choque, comiseração, desolação; nas palavras de Amiel, a "experiência estética, da emoção da forma, não intelectualizada ou objetivada, mas sentida, como uma apropriação" (AMIEL, 1998, p. 23). 


\section{Um amálgama de debilidade secundária}

Filhos do silêncio é o único filme deste nosso recorte que dialoga abertamente com uma linguagem mais clássica, pertencente mais solidamente aos cinemas industriais de ficção. Marlee Matlin é também a única atriz profissional que figura nessa lista de atores/atrizes que possuem algum tipo de condição ou afecção e que foram escolhidos para figurarem um personagem cinematográfico. Matlin é atriz, surda-muda, que interpreta uma personagem (Sarah) com problemas de interação social, pois se recusa a usar a língua falada como veículo de comunicação, atendo-se somente à língua de sinais (libras). William Hurt interpreta o professor, especialista em libras, que consegue um emprego na escola onde Sarah trabalha como zeladora. O filme é a história do atribulado encontro entre esse professor com métodos poucos convencionais de ensinar surdos e de uma jovem inteligente com profundos problemas de autorrejeição.

A inclusão de Matlin no elenco desse filme nos faz retornar à questão da autoridade da imitação com a ligeira diferença do grau de tal deficiência. $O$ tipo de afecção que acomete Matlin não é tão perceptível na tela quanto uma deformação como a de Madi Ekhtiar-dini, uma doença de cunho genético como a síndrome de Down do ator Pascal Duquenne ou mesmo dos anões Harry Earles e Alejandra Podestá. A presença plástica na tela desses atores é de um impacto imediato, enquanto que a surdo-mudez de Matlin é um dado secundário, mas que vai determinar a percepção visual e a construção social e narrativa da personagem.

$O$ fato de a atriz-personagem se comunicar por linguagens de sinais em nada modifica a decupagem, clássica aliás, do filme. Mantem-se o império do close, nos momentos de diálogos ferventes entre os protagonistas, excluindo o fato de a verdadeira comunicação entre eles se dar, na maioria das vezes, através das mãos, relegadas à borda do quadro ou ao fora de campo. Não existe exploração excessiva do seu corpo deficiente nem a inscrição gráfica desse corpo num ambiente hostil a ele - o filme se passa no meio de uma escola para surdos-mudos.

Quebrando com alguns parâmetros de verossimilhança, o filme faz o ator ouvinte, William Hurt, locucionar as frases ditas por Matlin em libras, o que torna as cenas levemente canhestras, diferentemente das interações cotidianas, em que os interlocutores raramente pronunciam as frases veiculadas pelos (as) surdos (as). Hurt se torna quase um ator épico dentro de um universo essencialmente dramático, pois tem que repetir em alto e bom tom o que os sinais comunicam - não somente seus, mas também os da sua parceira. As ilocuções de Hurt quebram com a fina camada de invisibilidade que separa a diegese (o 
mundo da história) do mundo do espectador, adquirindo um caráter de autoconsciência fílmica; ou seja, ao pronunciar os diálogos na linguagem das libras, o filme expõe um artifício que põe em comunicação direta os espaços diegético e extradiegético - o verdadeiro destinatário daquele diálogo não são mais os personagens, mas o espectador.

Diferente dos demais analisados, o tipo de amálgama ator-personagem que Marlee Matlin traz para esse corpus de filmes perfaz uma junção cujo grau de semelhança do ator com o personagem esteja em um nível de aceitação mais amplo, mais facilmente encontrável, do que atores com deformações tão visíveis. Nível de aceitação que se instaura também no âmbito do destino da personagem surda: o happy ending tão desbragado parece distante dos finais menos edificantes dos demais filmes. A tão buscada verossimilhança entre ator-personagem, ponto fulcral das demais atuações, transforma-se então em um dado secundário, submetido à busca pela empatia melodramática com a personagem feminina e à possibilidade de junção amorosa catártica entre os ambos.

\section{Considerações finais}

A experimentalidade desses filmes não está em fugir totalmente dos preceitos do classicismo atoral ditado por Stanislavski ou pelo Actor's Studio de Lee Strasberg e Stela Adler (sua versão cinematográfica), mas, em promover uma utilização do corpo do ator que o amalgame completamente ao do personagem pelo fato de terem um aspecto físico impossível de ser, pela chave da verossimilhança, imitado por um ator profissional. Esse amálgama completo, que é um sonho quase de origem do naturalismo, nunca, na verdade, foi buscado nos seus limites e nas suas condições mais radicais, pelo cinema clássico. Optou-se, quase sempre, pela edulcoração da questão, mesmo que isso ultrapassasse barreiras éticas cada vez mais intransponíveis na contemporaneidade - principalmente aquelas ligadas à representação étnica e de minorias sexuais, vide os recentes casos de denúncias de artifícios conhecidos como black-face e trans-fake.

Neste caso, o experimental no agenciamento do ator (casting) está promovendo algo que a cultura industrial do cinema clássico sistematicamente buscou sem, no entanto, ousar realmente: a busca pelos limites de uma total absorção do personagem pelo ator; no que tange no nosso exemplo, pelas marcas visíveis na tela do corpo do ator e suas deformações, sejam de ordem intelectual ou física. O amálgama total ator/personagem é procedimento com poder de desfamiliarização, pois descontrola os códigos de aplicabilidade da imagem do 
ator cinematográfico para um patamar tão absolutamente desconcertante, que abala, segundo Khouri (1980 citado por WILLIAMS, p. 46), as noções que nós temos de normatividade do corpo, do comum. Um estudo consistente acerca das relações do amálgama e da teoria brechtiana ainda resta a ser feito. Além desse desterramento de noções já cristalizadas sobre o corpo, o cinema é capaz efetivamente de repor em discussão a questão da diferença e da aceitação social do corpo acometido de condições especiais ou deformações em outros pilares: através da sugestão da relativização da diferença e da agressão ao público pelo seu caráter político e contestatório.

O ator deformado não pode "esconder ou apagar" por detrás da personagem o seu corpo-referência, ou seja, o seu corpo-identidade fora do filme, transformando-se no protótipo perfeito do conceito de homem dramático proposto por Peter Szondi (1959 citado por PAVIS, 2000, p. 145). Assim, a tricotomia corpo-do-ator/personagem/ator-interpretando-o-personagem se torna nessas aparições uma só entidade significante; uma necessariamente nos fazendo lembrar da outra, multiespiral de estímulos, revelação tácita do processo de criação do personagem por trás da camada de tintas transparente da narrativa. Uma quebra da transparência mimética cara a Brecht e seus discípulos cinematográficos.

O corpo acometido de condições de formação orgânica que contrasta com o comum, as deformações provocadas pelo envelhecimento, a decrepitude e a carnadura do corpo foram objeto de várias obras de arte, de uma miríade de artistas e pesquisadores interessados nos aspectos fenomenológicos da constituição corporal humana e, obviamente, do ator teatral e de cinema. Contudo, não foi só na ambiência das artes, da alta cultura das letras, do teatro, da literatura e do cinema industrial e moderno que esse interesse pelo corpo acometido de afecções físicas ou mentais nos interessa por razões benignas ou não.

A ambiência dos espetáculos mambembes, dos Circo de Horrores que apresentavam aberrações humanas como a mulher barbada, o homem mais forte do mundo, as irmãs siamesas ou a mulher que se transforma em gorila: os grotescos freaks shows foram presença marcante em qualquer cidade do mundo. Este tipo de espetáculo sempre atraiu a atenção do público, sequioso pelo aberrante, pelo deformado, pelo que lhe era impactante e diferente. Um caso igualmente chocante destes freaks shows foi o da mulher sul-africana Saartjie Baartman, exposta como aberração humana em trupes mambembes de exibições pseudoartísticas nos séculos XVIII e XIX, cuja história inspirou o biopic de Adellatif Kechiche, Vênus Negra (Vénus noire, 2010). 
Diferentemente dos freaks shows, empresas que caíram no ocaso, esses filmes com atores acometidos de afecções físicas ou mentais são empreitadas realistas com ares de denúncia social; o cinema mainstream já se enveredou pelo espetáculo do personagem acometido de afeção, quando David Lynch levou para as telas a história de John Merrick, em O homem elefante, interpretado brilhantemente pelo ator John Hurt, com ajuda de maquiagem pesada para dar vida ao homem acometido por uma rara doença chamada de síndrome de Proteus. O homem elefante não era uma tentativa de denúncia da nossa incapacidade de compreensão do que nos é diferente, mas uma possibilidade de redenção da população civilizada inglesa e europeia das barbáries ocorridas nesses freaks show, uma tentativa de redenção temática que passava, em grande parte, pela escolha de um ator não deformado para viver o personagem. Os filmes do nosso recorte, ao contrário, com exceção de Filhos do Silêncio e daqueles citados na primeira lista que abre esse artigo, talvez reponham em discussão o nosso pânico da semelhança por meio da simples exposição da exterioridade da carne, da mera materialidade da aparência. O grande trunfo desses filmes não é só da ordem experimental prático-teórica - promover o amálgama total ator-personagem - mas também trazer à tona essas afecções, revelar a existência muitas vezes desprezada desses seres humanos, que encontram no cinema uma ambiência onde o que imperava, até agora, era a sua quase total invisibilidade.

\section{Referências}

AMIEL, Vincent. Le corps au cinema: Keaton, Bresson, Cassavetes. Paris: Presses Universitaires de France, 1998.

AUMONT, Jacques. Du visage au cinema. Paris: Editions de l'Etoile/Cahiers du Cinéma, 1992.

BARTHES, Roland. Rhétorique de l'image. In: Communications 4, 1964. p. 40-51. Recherches sémiologiques. https://doi.org/10.3406/comm.1964.1027

BERGALA, Alain. L'invention de l'acteur moderne. 2005. Disponível em: https://www. cineclubdecaen.com/evenement/exceptiono4.htm. Acesso em: 31 jan. 2018.

BORDWELL, David. Figuras traçadas na luz. A encenação no cinema. Campinas: Papirus, 2008.

BOURGET, Jean-Loup. Hollywood, la norme et la marge. Paris: Armand Collin, 2005. 
BRENEZ, Nicole. De la figura en général e du corps en particulier - L'invention figurative au cinema. Louvain-la-Neuve: De Boeck, 1998. https://doi.org/10.3917/dbu.brene.1998.01

DAMOUR, Christophe (org.). Jeu d'acteurs - Corps et gestes au cinema. Strasbourg: Universitaires de Strassbourg, 2016. Col. Formes Cinématographiques. https://doi. org/10.4000/books.pus.6120

DE ESO no se habla. Direção: Maria Luisa Bemberg. Produção: Óscar Kramer; Roberto Cicutto. Intérpretes: Marcello Mastroianni, Luisina Brando, Alejandra Podestá, Betiana Blum, Roberto Carnaghi. Música: Nicola Piovani. Argentina: 1993. 1 fita de vídeo (106 min), VHS, son., color.

DYER, Richard. Stars. London: British Film Institute, 1998.

FARCY, Gérard-Denis; PRÉDAL, René (org.). Brûler les planches, Crever l'écran - La présence de l'acteur. Saint-Jean-de-Védas: L'Entretemps Éditions, 2001.

FILHOS do Silêncio (Children of a lesser God). Direção: Randa Raines. Produção: Candace Koethe e Burt Sugarman. Intérpretes: William Hurt, Marlee Matlin, Piper Laurie, Philip Bosco, Allison Gompf, John F. Cleary. Música: Michael Convertino. EUA: 1986. (119 min), son., color.

GALARD, Jean. A beleza do gesto: Uma estética das condutas. São Paulo: EDIUSP, 2008. Col. Críticas Poéticas, 7.

MIXON, Don. A theory of actors. Journal for the Theory of Social Behaviour, London, v. 1, n. 13, p. 97-110, 1983. https://doi.org/10.1111/j.1468-5914.1983.tbo0465.X

MONSTROS (Freaks). Direção e Produção: Tod Browning. Intérpretes: Wallace Ford, Leila Hyams, Olga Baclanova, Roscoe Ates, Henry Victor, Harry Earles, Daisy Earles, Rose Dione. EUA: 1932. 64 min., son., p\&b.

NACACHE, Jacqueline. $\mathbf{O}$ ator de cinema. Lisboa: Edições Texto \& Grafia, 2012.

NAREMORE, James. Acting in the cinema. Berkley: University of California Press, 1988.

NAREMORE, James. Film Acting and the Arts of Imitation. Film Quarterly, Oakland, v. 65, n. 4, p. 34-42, 2012. Disponível em: http://www.jstor.org/stable/10.1525/fq.2012.65.4.34 . Acesso em: 13 ago. 2016. https://doi.org/10.1525/FQ.2012.65.4.34

O OITAVO dia (Le huitième jour). Direção: Jacob Van Dormael. Produção: Philippe Godeau. Intérpretes: Daniel Auteuil, Pascal Duquenne, Miou-Miou, Henri Garcin, Isabelle Sadoyan, Michele Maes, Fabienne Loriaux. Música: Pierre Van Dormael. França: Philippe Godeau, 1996. (118 min), son., color.

PAVIS, Patrice. A análise dos espetáculos. São Paulo: Perspectiva, 2011. Col. Estudos. 
PAVIS, Patrice. Le personnage romanesque, théâtral, filmique. In: PAVIS, Patrice. Vers une théorie de la pratique théâtrale, Voix et images de la scène. Lille: Presses Universitaires du Septentrion, 2000.

ROUBINE, Jean-Jacques. A arte do ator. Rio de Janeiro: Jorge Zahar Editor, 2002.

SCHRÖPFER, Denise. Peut-on enseigner la présence?: La leçon de Yoshi Oida. In: FARCY, Gérard-Denis; PRÉDAL, René (dir.). Brûler les planches, Crever l'écran - La présence de l'acteur. Saint-Jean-de- Védas: L'Entretemps Éditions, 2001.

TEMPO de embebedar cavalos (Zamani barayé masti asbha). Direção e Produção: Bahman Ghobadi. Intérpretes: Ayoub Ahmadi, Rojin Younessi, Amaneh Ekhtiar-Dini, Madi Ekhtiar-Dini. Música: Hossein Alizadeh. Irã: Bahman Ghobadi, 2000. (100 min), son., color.

THOMPSON, Kristin. Breaking the glass armor - Neoformalist film analysis. Princeton, New Jersey: Princeton University Press, 1988.

WILLIAMS, Bruce. Dwarfing difference: Deformity at the threshold of the visible in Bemberg's I don't want to talk about it. Canadian Journal of Film Studies/ Revue Canadienne D'Études Cinématographiques, Ottawa, v. 8, n. 2, p. 44-55, 1999. https:// doi.org/10.3138/cjfs.8.2.44

\section{Dados dos autores:}

Pedro Maciel Guimarães Junior - pedromacielguimaraes@gmail.com

Professor do Departamento de Cinema e do Programa de Pós-Graduação em Multimeios, Instituto de Artes, Unicamp. Doutor pela Universidade Sorbonne Nouvelle - Paris 3.

\section{Sandro Oliveira - nagysandro1@gmail.com}

Professor nas áreas de História do cinema e linguagens audiovisuais no Curso de Cinema e Audiovisual na Universidade Estadual de Goiás - UEG. Doutorando em Multimeios pelo PPGMM-Unicamp e Mestre em Comunicação e Semiótica pelo PEPGCOS-PUC-SP.

Endereço dos autores: Universidade Estadual de Campinas, Instituto de Artes. Rua Elis Regina, 50, Cidade Universitária "Zeferino Vaz", Barão Geraldo, 13.083854 - Campinas (SP) - Brasil 